\title{
A ATUAÇÃO DA DEFENSORIA PÚBLICA NA REGULARIZAÇÃO FUNDIÁRIA URBANA DE INTERESSE SOCIAL EM ÁREA DE PRESERVAÇAO PERMANENTE
}

O Paradoxo entre a Preservação Ambiental e a Dignidade da Pessoa Humana

\author{
THE PERFORMANCE OF THE PUBLIC DEFENDER'S OFFICE IN URBAN LAND \\ PROPERTY REGULARIZATION OF SOCIAL INTEREST IN AREA OF \\ PERMANENT ENVIRONMENTAL PROTECTION
}

The paradox between the environmental preservation and the dignity of the human person

\section{Marina Lage Pessoa Costa \\ Elcio Nacur Rezende}

\begin{abstract}
Escola Superior Dom Helder Câmara - Belo Horizonte - Minas Gerais - Brasil
\end{abstract}
\begin{abstract}
Resumo: Este artigo tem por objeto a análise da regularização fundiária de interesse social prevista pela Lei n. ${ }^{\circ} 11.977$, de 07 de julho de 2009, denominada "Minha Casa, Minha Vida" notadamente em áreas de preservação permanente, ocupada pela população socialmente vulnerável. Aponta-se que regularização fundiária promove a inclusão social cidadã, bem como a preservação e o uso sustentável do meio ambiente, como forma de materialização da função socioambiental da propriedade urbana. A Defensoria Pública, instituição essencial à função jurisdicional do Estado, é instrumento jurídico e político da Política Urbana regulamentada pelo Estatuto da Cidade, com o dever de assegurar a assistência jurídica gratuita e integral, com atuação extrajudicial quanto judicial, de modo a promover a cidadania através do direito à moradia digna e integrada à cidade formal.
\end{abstract}

Palavras-chave: Área de Preservação Permanente. Defensoria Pública. Direito de moradia. População socialmente vulnerável. Regularização fundiária urbana.

\begin{abstract}
This article has as its object the analysis of agrarian regularization of social interest provided for in law No. 11,977, July 7, 2009, called "my house, my life" notably in permanent preservation areas, occupied by the socially vulnerable population. Points out that regularization promotes social inclusion, as well as the preservation and sustainable use of the environment as a way of materializing the environmental function of urban property. The Public Defender's Office, an institution essential to the jurisdictional function of the State's legal and political instrument of urban policy regulated by Statute of the city, with the duty to ensure that free legal assistance and integral, with extrajudicial action as judicial, in order to promote citizenship through the right to decent housing and integrated into the formal city.
\end{abstract}


Keywords: Permanent preservation area. Public Defender's Office. Right to housing. Socially vulnerable population. Urban agrarian regularization.

\section{CONSIDERAÇÕES INICIAIS}

Com o célere crescimento da industrialização no início do século $X X$, a população brasileira foi atraída para as cidades, as quais não estavam e nem foram preparadas para receber este contingente populacional.

O poder público por anos a fio olvidou das políticas públicas de habitação social.

Por outro lado, as exigências legais para a realização de um loteamento implicam em altos custos, que são repassados pelo empreendedor na venda dos lotes, o que alija parcela significativa da população da aquisição de uma propriedade regular.

Neste contexto, os economicamente desfavorecidos, por décadas, instalaram-se em moradias irregulares.

As áreas ocupadas ilegalmente são expressões diretas da ausência de políticas de habitação social, que sofrem não apenas com o problema da falta de imóveis adequados a moradia, mas notadamente a ausência da segurança da posse, que contribui para a precariedade das construções, e intensifica a vulnerabilidade desta parcela da população.

Esta realidade é um problema atual das cidades brasileiras, em especial as de grande e de médio portes, o que demanda planejamento e política pública adequada, eficaz e permanente.

O senso comum associa os assentamentos irregulares da população de baixa renda como produtores de poluição e de degradação ambiental, quando a equação é inversa, é justamente a população economicamente desfavorecida e mais vulnerável socialmente, quem menos produz os resíduos do sistema capitalista de produção, e mais suporta o ônus da degradação do meio ambiente. São duplamente punidos, já que excluídos da justa distribuição de riqueza pelo sistema capitalista, não possuem acesso ao espaço urbano formal, relegados a moradias 
não integradas a infraestrutura urbana, ao saneamento ambiental, ao transporte e serviços públicos.

A ocupação irregular, por vezes, encontra-se em área ambientalmente frágil, como as áreas de preservação permanente, por serem espaços urbanos que, via de regra, não estão ocupados pela cidade formal, considerando não só o conteúdo limitador da legislação aplicável, mas em especial em razão da ausência de interesse econômico do mercado imobiliário.

O Estatuto da Cidade, Lei n. ${ }^{\circ} 10.257$, de 10 de julho de 2001, em seu Capítulo II, trata dos instrumentos da política urbana, elencando como instrumentos jurídicos e políticos, dentre outros, a regularização fundiária; a assistência técnica e jurídica gratuita para as comunidades e grupos sociais menos favorecidos; a demarcação urbanística para fins de regularização fundiária; e a legitimação de posse.

Neste artigo trabalhar-se-á a regularização fundiária, a demarcação urbanística e a legitimação de posse, em áreas urbanas de preservação permanente, ocupadas pela população de baixa renda, regradas pela Lei n. ${ }^{\circ} 11.977$, de 07 de julho de 2009, sob o viés do papel da Defensoria Pública neste cenário, como instrumento da assistência jurídica gratuita para as comunidades e grupos sociais menos favorecidos.

A metodologia utilizada na consecução deste artigo consiste basicamente no método analítico-descritivo, tendo como fonte de pesquisa doutrina, informações eletrônicas e artigos científicos em revistas e sítios especializados. Utilizou-se também da experiência prática da atuação da Defensoria Pública na defesa do direito de moradia da população socialmente vulnerável nos procedimentos de regularização urbana.

Ao final este artigo concluirá que a regularização fundiária de áreas urbanas consolidadas, inclusive as que incidem em área de preservação permanente, ocupadas pela população socialmente vulnerável, é o instrumento adequado para compatibilizar o direito social à moradia, a cidadania, a preservação ambiental e o planejamento urbano.

A Defensoria Pública deve agir de modo proativo fomentando a regularização fundiária urbana prevista pela Lei n. ${ }^{0} 11.977$, de 07 de julho de 2009, REVISTA DO DIREITO UNISC, SANTA CRUZ DO SUL 
considerando que a moradia regular e integrada à cidade formal é condição para a realização de outros direitos constitucionais, como o trabalho, o lazer, a educação, a saúde, e da proteção ambiental, o que implica na materialização da dignidade da pessoa humana.

\section{Assentamento irregular da população socialmente vulnerável}

No Brasil, o processo de urbanização é marcado pela dualidade entre a cidade formal e a cidade informal, o que reflete a desigualdade social e de distribuição da riqueza, característica do país.

A falta de planejamento e o célere crescimento da população urbana contribuíram para este atual cenário. Segundo Ermínia Maricato (2009, p. 269):

Em 1940, o Brasil tinha 30\% da população vivendo nas cidades. Em 2000, essa população chegou a $81 \%$, com quase 130 milhões de moradores urbanos, caracterizando um processo rápido de urbanização do país, que aconteceu especialmente durante o século XX.

As cidades brasileiras convivem com um passivo da ausência de políticas sociais habitacionais. Grande é o contingente populacional que vive em loteamentos irregulares, entendidos como aqueles que no trâmite burocrático quedaram pendentes de legalização perante o ente público, ou mesmo clandestinos, aqueles que sequer foram objeto de formalização legal.

Além dos loteamentos irregulares e clandestinos, é também realidade do espaço urbano as ocupações ilegais, que ocorrem sem planejamento, geralmente com autoconstruções e com grande adensamento populacional, em locais sem infraestrutura pública, e precária (quando existente) prestação de serviços urbanos, tais como água, esgoto, coleta de lixo, drenagem, iluminação pública, varrição, transporte público, equipamentos da rede pública de saúde e ensino, dentre outros.

Ermínia Maricato (2003, p.80) apresenta a diferença entre os loteamentos ilegais e as favelas no seguinte sentido:

O que define a favela é a completa ilegalidade da relação do morador com a terra. Trata-se de áreas invadidas. O que a difere dos loteamentos ilegais é o contrato de compra e venda que garante algum direito ao morador do loteamento, também chamado popularmente de loteamento clandestino. Muitas são as variantes que o loteamento ilegal pode assumir. Em geral a

REVISTA DO DIREITO UNISC, SANTA CRUZ DO SUL 
ilegalidade pode estar na burla às normas urbanísticas: diretrizes de ocupação do solo, dimensões dos lotes, arruamento, áreas públicas e institucionais, que devem ser doadas para o poder público, estão entre as mais comuns. Há casos entretanto, em que a ilegalidade está na documentação de propriedade, na ausência da aprovação do projeto pela prefeitura ou no descompasso entre o projeto aprovado e sua implantação. A irregularidade na implantação do loteamento impede o registro do mesmo pelo cartório de registro de imóveis, prejudicando, consequentemente, os compradores.

O loteamento ilegal e a favela são as alternativas mais comuns de moradia da maior parte da população urbana de renda baixa e média baixa. Foi a "solução" que o desenvolvimento urbano, no Brasil, deu para grande parte dos moradores das grandes cidades.

A Lei n. ${ }^{\circ} 11.977$, de 07 de julho de 2009, conceitua como assentamentos irregulares as ocupações inseridas em parcelamentos informais ou irregulares, localizadas em áreas urbanas públicas ou privadas, utilizadas predominantemente para fins de moradia (art.47, VI).

É da ordem do dia que os Municípios formulem agendas propositivas, e adequadas políticas públicas habitacionais visando sanear este passivo de segregação socioambiental e espacial.

Não se pode perder de vista no planejamento público que os assentamentos irregulares não se deram por ato de escolha ou liberalidade dos possuidores, mas justamente pela falta de escolha e de opção para exercerem o direito social de moradia, como resultado da injusta distribuição e exclusão socioeconômica, razão pela qual o tratamento a esta população vulnerável deve ser reparador $\mathrm{e}$ compensador, e não com viés punitivo.

Os assentamentos apresentam normalmente dois tipos de irregularidade fundiária: irregularidade dominial, quando o possuidor ocupa uma área pública ou privada, sem qualquer garantia jurídica sobre a propriedade; e a irregularidade urbanística e ambiental, quando o parcelamento não está de acordo com a legislação urbanística e ambiental.

A efetiva integração da população moradora da cidade informal à cidade formal requer o enfrentamento de todas essas questões acima citadas, por isso a regularização fundiária envolve um conjunto de ações. Além disso, quando se trata de assentamentos de população de baixa renda, são necessárias também medidas sociais, de forma a buscar plena inserção das pessoas à cidade. 
O instrumento adequado para equacionar este problema social, habitacional, urbanístico e ambiental é a regularização fundiária, que visa à permanência da população no local em que estabeleceram moradia, legalizando as áreas urbanas ocupadas informalmente, com consequente melhoria do ambiente urbano e da qualidade de vida.

A moradia irregular gera insegurança permanente na população. Contudo a efetiva democratização do acesso à moradia perpassa por uma política de habitação social que vai além da concessão de títulos de uso ou de propriedade, mas da moradia digna, ou seja, aquela que conjuga habitação com integração do cidadão à cidade através da mobilidade, da infraestrutura, da disponibilização de equipamentos da rede de serviços públicos - saúde e educação, saneamento, áreas de lazer.

É essencial que a população conheça seus direitos e possua em todo o procedimento orientação e assistência jurídica, de forma a bem reivindicar e concretizar seus direitos previstos.

\section{A Defensoria Pública como instrumento jurídico e político da política urbana}

A Constituição de 1988 instituiu, no art. 134, a Defensoria Pública como o ente estatal autônomo e responsável pela concretização do direito fundamental à assistência jurídica integral e gratuita.

A Lei Complementar Federal n. ${ }^{\circ}$ 80, de 12 de janeiro de 1994, lei orgânica da Defensoria Pública, dispõe que a Defensoria Pública é instituição permanente, essencial a função jurisdicional do Estado, expressão e instrumento do regime democrático. São objetivos da Defensoria Pública a primazia da dignidade da pessoa humana e a redução das desigualdades sociais; a afirmação do Estado Democrático de Direito; a prevalência e efetividade dos direitos humanos; e a garantia dos princípios constitucionais da ampla defesa e do contraditório.

Reconheceu o constituinte brasileiro a necessidade de estruturar uma instituição voltada para a parcela da população que sofre os efeitos nefastos da desigualdade social sobre $\mathrm{o}$ direito a ter direitos, encarregada de promover a igualdade de condições do pleno acesso à ordem jurídica justa.

REVISTA DO DIREITO UNISC, SANTA CRUZ DO SUL

№. 44 | p.25-49| SET-DEZ 2014 
A todos impossibilitados de contratar um advogado, oportuniza-se de forma gratuita um Defensor Público com a mesma envergadura do profissional escolhido e remunerado pelo indivíduo afortunado.

A Defensoria incumbe-se da orientação jurídica e defesa dos direitos individuais e coletivos dos necessitados, nos termos do art. 134 da Constituição da República.

Ada Pelegrini Grinover, em parecer exarado no bojo da ADI 3943, interpreta o conteúdo constitucional do termo "necessitados" afirmando que, além dos necessitados econômicos, existem os socialmente vulneráveis, chamados de necessitados do ponto de vista organizacional:

(...) existem os que são necessitados no plano econômico, mas também existem os necessitados do ponto de vista organizacional. Ou seja, todos aqueles que são socialmente vulneráveis: os consumidores, os usuários de serviços públicos, os usuários de planos de saúde, os que queiram implementar ou contestar políticas públicas, como as atinentes à saúde, à moradia, ao saneamento básico, ao meio ambiente etc.

A assistência jurídica gratuita prestada pela Defensoria Pública transcende, em muito, a formal postulação no processo judicial ou administrativo, uma vez que a norma constitucional a caracterizou de integral.

Destarte, engloba, além do patrocínio técnico perante o poder judiciário, a atuação extrajudicial, que compreende a consultoria gratuita, a informação e orientação jurídica, a conscientização e educação em direitos, e a possibilidade de acesso aos meios alternativos de resolução de conflitos que viabilizem a prevenção ou exclusão de demanda judicial.

O papel do Defensor Público é de busca por soluções, de pacificação social, que por vezes não perpassa pelo Poder Judiciário. É na atuação extrajudicial que resta claro o papel do Defensor Público como agente de transformação social.

Dada a essencialidade da atuação da Defensoria Pública em prol dos vulneráveis sociais, a instituição vem nos últimos anos se fortalecendo a fim de bem cumprir sua missão.

A proximidade com as questões sociais naturalmente demonstrou a necessidade de expressa legitimação da Defensoria Pública para a ação civil 
pública, o que foi realizado pela edição da Lei n. 11.488, de 15 de junho de 2007, que alterou o inciso II do artigo $5^{\circ}$ da Lei n. 7.347, de 24 de julho de 1985.

Aliás, a alteração legislativa na Lei da Ação Civil Pública, em verdade, veio a ser um reconhecimento do trabalho já desempenhado pela Defensoria Pública em demandas coletivas, seja por meios de resolução extrajudicial de conflitos coletivos, seja pelo próprio ajuizamento de ações coletivas, com fundamento no art. 82, III, do Código de Defesa do Consumidor, e no art. 21 da Lei da Ação Civil Pública. Esta anterior atuação se dava considerando a natureza dos direitos envolvidos, bem como a ampliação do acesso à justiça para além das demandas individuais.

Está em trâmite perante o Supremo Tribunal Federal a Ação Direta de Inconstitucionalidade (ADI) n. ${ }^{\circ}$ 3943, ajuizada pela Associação Nacional dos Membros do Ministério Público (CONAMP), que contesta lei que legitimidade da Defensoria Pública para propor ação civil pública.

A CONAMP alega que a possibilidade da Defensoria Pública propor, sem restrição, ação civil pública afeta diretamente as atribuições do Ministério Público, posto que segundo a associação, a lei contraria os artigos $5^{\circ}$, LXXIV, e art. 134, da Constituição de 1988, vez que a Defensoria Pública somente seria legitima a prestar assistência jurídica integral e gratuita aos que não possuem recursos financeiros suficientes.

Sustenta a CONAMP que os beneficiados pela atuação da Defensoria Pública devem ser, pelo menos, identificáveis, o que excluiria a defesa de interesses metaindividuais que beneficiasse "não necessitados".

Com o devido respeito, este posicionamento não se alinha à finalidade da ação civil pública que visa a ampla proteção dos direitos difusos, coletivos e individualmente homogêneos. A legitimidade para propositura da ação civil pública é concorrente e disjuntiva justamente para alargar o espectro de acesso à justiça. Não existe monopólio ou maior importância de um legitimado em face de outro, e ampliar o rol de legitimados não vulnera e nem fere as atribuições do Ministério Público, que não deixou tê-las. Aliás, ciente de situação que enseje a propositura de ação civil pública, não só pode, como deve, o Ministério Público agir, de modo que não deve ser objeto de sua preocupação a eventual ação e/ou diligências da Defensoria 
Pública, que se (também) vier a agir, estará simplesmente ampliando o acesso à justiça, o que é interesse de toda a sociedade.

A legitimidade da Defensoria Pública é mais uma das vias e formas de defesa dos direitos e interesses sociais, podendo todos os legitimados, inclusive Defensoria Pública e Ministério Público, agirem em litisconsórcio, não havendo assim motivo razoável a oposição do Ministério Público, que é instituição essencial à função jurisdicional do Estado tanto quanto a Defensoria Pública.

$\mathrm{O}$ art. $4^{\circ}$ do Estatuto da Cidade, em seu inciso $\mathrm{V}$, alínea $r$, prevê como instrumento da política urbana, no viés jurídico e político, a assistência técnica e jurídica gratuita para as comunidades e grupos sociais menos favorecidos.

O $\S 5^{\circ}$ do $\operatorname{art}^{\circ} 4^{\circ}$ da Lei Complementar Federal n. ${ }^{\circ} 80$, de 12 de janeiro de 1994, Lei Orgânica da Defensoria Pública estabelece que a assistência jurídica integral e gratuita custeada ou fornecida pelo Estado será exercida pela Defensoria Pública.

Destarte, a Defensoria Pública é a instituição que concretiza o instrumento da política urbana mencionado pelo Estatuto da Cidade, sendo seu papel promover a assistência jurídica integral e gratuita para a coletividade socialmente vulnerável.

Incumbe a Defensoria Pública a atuação extrajudicial junto ao poder público, como interlocutora e instrumento de assistência jurídica dos possuidores vulneráveis, e atuação judicial, quando for o caso, com vistas a promover a regularização fundiária, de modo a conciliar moradia digna e justiça ambiental, assegurando meio ambiente ecologicamente equilibrado para todos.

Dentre as funções institucionais da Defensoria Pública, elenca a Lei Complementar n. ${ }^{\circ} 80$, de 12 de janeiro de 1994 , no inciso $X$ do art. $4^{\circ}$, promover a mais ampla defesa dos direitos fundamentais dos necessitados, abrangendo seus direitos individuais, coletivos, sociais, econômicos, culturais e ambientais, sendo admissíveis todas as espécies de ações capazes de propiciar sua adequada e efetiva tutela.

\section{A regularização fundiária em prol da população de baixa renda moradora de área urbana de preservação permanente e o paradoxo com o princípio do meio ambiente ecologicamente equilibrado}

REVISTA DO DIREITO UNISC, SANTA CRUZ DO SUL

№. 44 | p.25-49 | SET-DEZ 2014 
A Lei Federal n. ${ }^{0} 11.977$, de 07 de julho de 2009, define no art. 47 a regularização fundiária como o conjunto de medidas jurídicas, urbanísticas, ambientais e sociais que visam à regularização de assentamentos irregulares e à titulação de seus ocupantes, de modo a garantir o direito social à moradia, o pleno desenvolvimento das funções sociais da propriedade urbana e o direito ao meio ambiente ecologicamente equilibrado.

Betânia Alfonsin (2001, p.24), definiu regularização fundiária como:

\begin{abstract}
o processo de intervenção pública, sob os aspectos jurídico, físico e social, que objetiva legalizar a permanência de populações moradoras de áreas urbanas ocupadas em desconformidade com a lei para fins de habitação, implicando acessoriamente melhorias no ambiente urbano do assentamento, no resgate da cidadania e da qualidade de vida da população beneficiária.
\end{abstract}

Estabelecer moradia em um endereço reconhecido pelo poder público é expressão da cidadania, razão pela qual a regularização fundiária deve ser articulada com outras políticas públicas para transformar uma ocupação urbana ilegal em um território legal integrado à cidade.

Nessa perspectiva, para orientar a utilização da regularização fundiária, instrumento de política urbana, a Lei no 11.977, de 07 de julho de 2009, estabeleceu importantes princípios a serem observados neste procedimento, tais como: a ampliação do acesso à terra urbanizada pela população de baixa renda, com prioridade para sua permanência na área ocupada, assegurando nível adequado de habitualidade e melhoria das condições de sustentabilidade urbanística, social e ambiental; articulação com as políticas setoriais de habitação, de meio ambiente, de saneamento básico e de mobilidade urbana, voltadas a integração social e à geração de emprego e renda; participação dos interessados em todas as etapas do processo de regularização; e estímulo à resolução extrajudicial de conflitos.

Interessa a este artigo a regularização fundiária de assentamentos urbanos de interesse social, previstos pelo inciso VII do art.47 da Lei n. ${ }^{0} 11.977$, de 07 de julho de 2009, que os define como assentamentos irregulares ocupados, predominantemente, por população de baixa renda, nos casos: a) em que a área esteja ocupada, de forma mansa e pacífica, há, pelo menos, 5 (cinco) anos; b) de 
imóveis situados em ZEIS; ou c) de áreas da União, dos Estados, do Distrito Federal e dos Municípios declaradas de interesse para implantação de projetos de regularização fundiária de interesse social.

Ponto importante na atuação da Defensoria Pública na regularização fundiária urbana de interesse social, em área de preservação permanente, é o aparente paradoxo entre a preservação ambiental e a dignidade da pessoa humana.

De modo ideal, não deveria haver ocupação humana para fins de moradia em áreas de preservação permanente. Entretanto, estas ocupações de fato existem e precisam ser regularizadas pelo poder público, o que inclusive é objeto de reconhecimento legal pelo $\S^{\circ}$ do art. 54 da Lei 11.977, de 07 de julho de 2011.

O $\S 1^{\circ}$ do art. 54 da Lei n. ${ }^{0} 11.977$, de 07 de julho de 2009, prevê a possibilidade de regularização fundiária de interesse social em áreas de preservação permanente ocupadas até 31 de dezembro de 2007 e inseridas em área urbana consolidada, uma vez comprovado que esta intervenção implica em melhoria das condições ambientais em relação à situação irregular anterior.

Registre-se que ao estabelecer um marco legal para possibilidade de regularização fundiária de interesse social em áreas de preservação, o poder público deve trabalhar em duas frentes.

Uma atuando de forma a evitar novas ocupações em áreas de preservação permanente, resguardando-as para as presentes e futuras gerações.

Outra, regularizando e agindo em prol das situações consolidadas ao longo do período de omissão do poder público, que após anos e anos de ocupações informais, gerou direitos para os ocupantes destas áreas. Não se pode desconsiderar a realidade das cidades brasileiras, notadamente as regiões metropolitanas, em que grande parte dos assentamentos irregulares encontram-se em topos de morros, serras e em áreas próximas de cursos d’água.

Importante considerar que as ocupações ilegais consolidadas não decorreram apenas da omissão do poder público, mas de seu próprio fomento. $O$ poder público não só deixou de adotar medidas para evitar, ou contornar, a ocupação ilegal quando de seu surgimento, como a estimulou e a reconheceu, quando da promoção e instalação de serviços públicos essenciais para a moradia (ainda que precária e irregular) daquela população, tais como iluminação pública, ou REVISTA DO DIREITO UNISC, SANTA CRUZ DO SUL 
rede de saneamento, ou abastecimento de água potável, ou coleta de resíduos e limpeza urbana, ou transporte público, ou rede pública de saúde e educação.

A omissão do poder público quanto a políticas sociais habitacionais, somada a sua ação de fomento a ocupação irregular, por anos e anos, gerou expectativas e direitos aos possuidores em ocupações ilegais, em áreas de preservação permanente inclusive.

Assim, as ocupações irregulares e consolidadas da população socialmente vulnerável, ainda que em área de preservação permanente, devem ser regularizadas. Para tanto, essencial se mostra a compatibilização da dignidade humana e do equilíbrio ambiental.

Tem-se que ter em mente que tanto a proteção ambiental quanto o direito à moradia são valores constitucionais da ordem jurídica brasileira, que conforme afirma Edésio Fernandes, possuem a mesma raiz conceitual, qual seja, o princípio da função socioambiental (2006, p.357).

O saneamento das ocupações informais em áreas ambientalmente frágeis, objeto de impositiva preservação legal, busca conciliar a recuperação e/ou preservação ambiental com o direito à moradia da população socioeconomicamente desfavorecida.

Deve ser destacado que promover a regularização fundiária de área ambientalmente frágil ocupada pela população de baixa renda, antes de implicar flexibilização da proteção ambiental, importa na efetiva recuperação ambiental e social.

Ao mesmo tempo em que assegura o direito de moradia digna, o poder público terá a possibilidade de controlar e promover políticas e planejamento de proteção ambiental de uma área que antes estava fora de seu alcance e planejamento, fadada ao desgaste e degradação ambiental, sem uso racional e sustentável.

As políticas públicas e a educação ambiental passam a ter possibilidade real de eficácia a partir do momento em que a população, até então excluída da cidade formal, a ela é integrada, e passa a ter não só a sensação de pertencimento, como instrumentos factíveis de proteção ambiental. 
O procedimento de regularização fundiária de área de preservação permanente pode assegurar, em especial se realizada com articulação e participação popular, áreas de reflorestamento, medidas mitigadoras $\mathrm{e}$ compensatórias, tornando o local sustentável sob o viés socioambiental.

Quando a regularização fundiária de interesse social incidir em área de preservação permanente (para os casos de ocupações até 31 de dezembro de 2007 e inseridas em áreas urbanas consolidadas) além do projeto de regularização, deve ser realizado estudo técnico com os seguintes dados: caracterização da situação ambiental da área a ser regularizada; especificação dos sistemas de saneamento básico; proposição de intervenções para o controle de riscos geotécnicos e de inundações; recuperação de áreas degradadas e daquelas não passíveis de regularização; comprovação da melhoria das condições de sustentabilidade urbanoambiental, considerados o uso adequado dos recursos hídricos e a proteção das unidades de conservação, quando for o caso; comprovação da melhoria das condições da habitualidade dos moradores propiciada pela regularização proposta; e garantia de acesso público às praias e aos corpos d'água, quando for o caso. $O$ que importa dizer, implicará em um estudo multidisciplinar com diretrizes e plano para a compatibilização entre direito social de moradia e função socioambiental da propriedade.

A Defensoria Pública deve acompanhar a elaboração do projeto de regularização e ser o interlocutor da população diretamente interessada com o Poder Público. Essa interlocução, se traduz na orientação pelo Defensor Público aos possuidores, através de linguagem fácil e acessível, do que na prática, o projeto de regularização significará, ou seja, onde haverá a abertura de vias públicas, a construção da infraestrutura urbana na região, a salvaguarda de áreas de risco e de determinados espaços ambientais sensíveis que devem ser objeto de proteção. $O$ Defensor Público tem que promover o empoderamento popular ao possibilitar a compreensão e debate pela população sobre o projeto elaborado, o que importará na efetiva participação dos diretamente atingidos na construção da regularização fundiária.

Nenhum direito é absoluto. Não se deve promover a remoção da população ocupante de determinada área de preservação ambiental sob o fundamento da REVISTA DO DIREITO UNISC, SANTA CRUZ DO SUL 
preservação ambiental. E nem mesmo conceder título de propriedade ou concessão de uso, ou legitimação de posse, sob o fundamento do direito de moradia e dignidade humana.

Há que se compatibilizar esses direitos, nas áreas já ocupadas de modo consolidado, construindo-se a sustentabilidade pelo uso e ocupação racional e adequado destas área de preservação permanente. $O$ instituto legal, social, urbanístico e ambiental a promover esta compatibilização é a regularização fundiária, e seu instrumento é o projeto de regularização.

Defende-se a possibilidade de regularização do morador em área de preservação permanente, seja pela usucapião, seja pela proteção possessória, desde que respeitados os limites estabelecidos pelos estudos técnicos do projeto, tais como a não ocupação de áreas de risco e adoção de medidas que contornem ou evitem a degradação ambiental.

Os técnicos responsáveis pela elaboração do projeto de regularização devem indicar as ações necessárias a serem tomadas pelo poder público para que a ocupação não implique em poluição de mananciais, ou que a degradação ambiental ocorra ou aumente.

Destaque-se que toda e qualquer ocupação do ser humano implica em alteração do meio ambiente natural e gera impacto ambiental. O que se discute é o limite aceitável deste impacto de forma a permitir a moradia, mas não vulnerar ou violar o direito difuso ao meio ambiente ecologicamente equilibrado. O equilíbrio decorre do desenvolvimento sustentável, ou seja, o uso sem comprometer a função ecológica.

Portanto, nem toda construção estabelecida na ocupação irregular consolidada poderá ser objeto de regularização fundiária, resultando na remoção daqueles moradores. O mesmo ocorrerá em relação às áreas de risco, pois a proteção do direito à moradia não pode importar em risco de morte para o cidadão.

Assim, não é porque a área é de preservação permanente que será removida toda a população moradora consolidada. E não é porque se defende o direito à moradia que toda edificação é passível de regularização fundiária.

Dado curioso é perceber que há menor resistência da opinião pública (quando não da efetiva prática) a regularização de moradia irregular construída em REVISTA DO DIREITO UNISC, SANTA CRUZ DO SUL 
áreas de preservação permanente pela população de alta classe socioeconômica àquela a ser promovida em favor da população vulnerável socioeconomicamente. $\mathrm{O}$ adensamento populacional, as casas sem beleza ou luxo arquitetônico, estimulam o apoio do senso comum a remoção daqueles moradores vulneráveis. Para o meio ambiente e sua preservação, não qualquer diferença a classe socioeconômica dos moradores, sendo que a Defensoria Pública busca assegurar a igualdade de direitos e oportunidades aos menos favorecidos socioeconomicamente.

A regularização fundiária estabelecida pela Lei $n^{0} 11.977$, de 07 de julho de 2009, trabalha duas vertentes jurídicas, uma voltada para a legitimação de posse sobre o imóvel, a qual não implica em alteração do domínio dos bens imóveis que incidirem, sendo contudo importante instrumento a gerar segurança à posse.

A outra vertente jurídica decorrente da regularização fundiária regulada pela citada legislação é a aquisição da propriedade, através da inovadora usucapião extrajudicial ou administrativa.

Inova-se com a possibilidade de aquisição da propriedade por meio da usucapião administrativa, após a legitimação de posse realizada pelo poder público, com sua averbação e registro. Transcorrido o prazo legal da usucapião, a legitimação de posse será convertida em título de propriedade, por ato do oficial do Registro de Imóveis, a requerimento do interessado. Registre-se que a usucapião administrativa é restrita as hipóteses em que não haja oposição do proprietário do imóvel objeto do assentamento.

O fluxo administrativo estabelecido pela Lei n. $^{\circ} 11.977$, de 07 de julho de 2009, é desenvolvido em várias etapas que culminam no processo de regularização fundiária com a aquisição originária da propriedade por via extrajudicial.

De modo sumário, dispõe-se as fases deste procedimento administrativo visando facilitar a compreensão: levantamento de dados técnicos urbanísticos, ambientais e socioeconômico dos possuidores, para elaboração da demarcação urbanística e do projeto de regularização fundiária. Após o registro do parcelamento, é realizada a abertura das matrículas dos lotes, o procedimento de legitimação de posse, após o prazo legal estabelecido, titulação e registro imobiliário.

A usucapião administrativa, notadamente para as áreas de preservação permanente é vantajosa para toda a coletividade, uma vez que além de ser modo de REVISTA DO DIREITO UNISC, SANTA CRUZ DO SUL 
aquisição do domínio, materializa a cidadania ao integrar aqueles moradores (agora proprietários) à cidade formal através de ações e planejamentos urbanísticos, compatibilizando o direito social de moradia com a proteção ambiental da área de preservação.

As demais modalidades de usucapião, que demandam processo judicial, dispensam o projeto de regularização fundiária, conforme previsão da própria Lei $n$. $^{\circ}$ 11.977, de 07 de julho de 2009 , no $\S 1^{\circ}$ do art.51, o que significa dizer que, apesar da aquisição do domínio, o novo proprietário ainda estará alijado da integração com à cidade formal e seus benefícios e equipamentos públicos, frutos do procedimento administrativo de regularização fundiária.

A demarcação urbanística somente pode ser feita pelo poder público, ou seja, pela União, Estados, Municípios e Distrito Federal. É um procedimento administrativo no âmbito da regularização fundiária de interesse social.

Para a regularização fundiária de interesse social deve ser realizado o projeto de regularização fundiária, o qual deve considerar as características da ocupação e da área ocupada, visando definir parâmetros urbanísticos e ambientais específicos, além de indicar os lotes, as vias de circulação e as áreas destinadas a uso público (art.54, Lei n. $\left.{ }^{\circ} 11.977 / 2009\right)$. Destarte, o projeto é um instrumento que integra as dimensões social, jurídica, urbanística e ambiental que caracterizam a regularização fundiária.

Importante destacar que estes instrumentos de política urbana para assentamentos irregulares consolidados levam em consideração o contexto e características da cada realidade, admitindo-se parâmetros especiais de parcelamento, uso e ocupação do solo, inclusive área mínima dos lotes, para a regularização fundiária.

Realizada a demarcação urbanística e o projeto de regularização fundiária, prevê a Lei n. ${ }^{\circ} 11.977$, de 07 de julho de 2009, o instrumento da legitimação de posse, instituto que reconhece a posse exercida por moradores de áreas objeto de demarcação urbanística. É o reconhecimento pelo poder público da situação de fato, ou seja, a posse mansa e pacífica de pessoas que não possuem título de propriedade ou de concessão, bem como não sejam foreiras de outro imóvel urbano ou rural. 
A legitimação de posse culmina em título emitido pelo poder público, que gera segurança à posse daqueles moradores, que será objeto de registro no cartório de registro de imóveis, dando-se assim a devida publicidade e legitimidade a essa situação fática.

O regramento da Lei n. ${ }^{0} 11.977$, de 07 de julho de 2009, é um avanço, na medida em que resta expressa a preocupação do poder público na regularização fundiária de assentamentos urbanos informais, mantendo os possuidores no local de moradia, em contraposição a políticas de mera remoção e dispersão para locais longínquos e periféricos, como se não integrassem a própria cidade.

O procedimento legal previsto é complexo, tratando-se de uma intervenção pública, que deve envolver equipe multidisciplinar, composta por profissionais do direito, da área social e da área técnica, em trabalho integrado, democrático e participativo, sendo neste cenário essencial o papel proativo da Defensoria Pública, como agente de transformação social.

Da atuação da Defensoria Pública em conflitos fundiários urbanos, constatase a complexidade de se manejar judicialmente a usucapião urbana, notadamente a coletiva, em razão da prova técnica pericial. E ainda, as modalidades judiciais de usucapião, como já salientado, apesar de importante modo originário de aquisição da propriedade, não asseguram e nem substituem a demarcação urbanística e projeto de regularização necessários para a área.

É importante papel do Defensor Público atuar extrajudicialmente junto ao poder público, notadamente o Município, fomentando a regularização fundiária com projeto de urbanização, indo além da segurança da posse e da concessão de título de propriedade, de modo a assegurar a inclusão social e a materialização da cidadania, que decorrem da integração das comunidades em áreas informais na estrutura formal da cidade, e da sociedade urbana num geral.

Nesta atuação extrajudicial é essencial que a Defensoria Pública preste a assistência jurídica à comunidade interessada também no que se refere as indenizações.

Como já destacado, no bojo do projeto de regularização, nem toda edificação poderá ser regularizada, considerando que a abertura de vias públicas, a construção da infraestrutura urbana na região, a salvaguarda de áreas de risco e de REVISTA DO DIREITO UNISC, SANTA CRUZ DO SUL 
determinados espaços ambientais sensíveis, podem implicar na remoção e/ou realocação de alguns possuidores, restando ao Município, ou ente político responsável pelo procedimento, a indenização dessas edificações.

As edificações objeto de remoção não geram legitimação de posses.

Considerados possuidores de boa-fé, estes moradores no procedimento de desapossamento, têm o direito de indenização pela benfeitoria realizada no local, e via de regra, são indenizados pelo valor da construção, sem qualquer valoração da posse por eles exercidas na área.

Se proprietários fossem, aqueles moradores seriam desapropriados pelo poder público quando da regularização fundiária, caso a demarcação urbanística indicasse a necessidade da área daquele imóvel para o projeto de regularização. Com a desapropriação receberiam prévia e justa indenização, a qual abarcaria não só o valor da construção, como o valor do terreno.

O acesso a moradia está ligado ao seu preço, que varia de acordo com a localização na cidade (SILVA, 2011, p.224), ou seja, as vantagens e/ou desvantagens de acesso a serviços e equipamentos públicos, segurança, lazer, que determinada região permite. Valorar para fins de indenização apenas a edificação, sem considerar a região na qual está inserida, e as facilidades de acesso que aqueles moradores possuem, por exemplo, a transporte público, rede pública de saúde e ensino, é forma de privilegiar e tutelar a propriedade em detrimento da posse, além de violar direitos e garantias dos possuidores.

Esta é uma questão de extrema importância de ser trabalhada extrajudicialmente pela Defensoria Pública junto ao poder público e a população local.

Os avanços do procedimento extrajudicial e a regularização fundiária podem não ser de interesse da determinada população local receosa que este processo implique em sua remoção, que nesta hipótese, sofrerá significativa perda patrimonial.

Isso porque, se estes possuidores ingressassem com ação judicial de usucapião e comprovassem os requisitos necessários, adquiririam o domínio de sua moradia. Sendo titular do domínio, das duas uma, ou o poder público faria a 
regularização fundiária de modo a não removê-lo, ou procederia a desapropriação, arcando com a indenização justa (terreno mais edificação).

Assim, na prática, se não assegurada a justa indenização pela posse prolongada em terreno objeto de demarcação urbanística e projeto de regularização, permanecerá o interesse nas modalidades de usucapião judicial (mesmo atendidos os requisitos estabelecidos pelo inciso VII do art.47 da Lei n. ${ }^{0} 11.977$, de 07 de julho de 2009).

Não restam dúvidas quanto a importância social, urbanística e ambiental do procedimento da Lei n. ${ }^{\circ} 11.977$, de 07 de julho de 2009, mas não se pode desconsiderar também a importância do viés econômico da comunidade possuidora que terá de ser removida para a regularização fundiária, sendo que já teria direito, em tese, de adquirir o domínio pela usucapião judicial.

Nesta senda, visando compatibilizar os institutos, os interesses dos possuidores, e os interesses sociais, urbanísticos e ambientais envolvidos, deve o Defensor Público ser agente interlocutor junto ao poder público para assegurar que a indenização devida aos eventuais possuidores a serem removidos através do desapossamento para a regularização fundiária - possuidores estes que já possuíam os requisitos para a usucapião judicial - seja justa assim como na desapropriação, ou seja, que englobe o valor do terreno e da construção.

Este é o posicionamento defendido por Cleide Aparecida Nepomuceno (2013, p.163-164):

Em suma, a Defensoria Pública defende, em atendimento às demandas levadas ao seu conhecimento, que os procedimentos de desapropriações de imóveis sem títulos devem receber uma indenização pela edificação (benfeitorias) e pelo valor do lote, considerando a posse com os mesmos direitos da propriedade. E no caso de Vilas e Favelas, se o poder público visualizar a necessidade de derrubar alguma casa em função de obras públicas, ou mesmo por situação que coloque a vida dos moradores em risco, deve indenizar as benfeitorias e a posse, se esta tiver as características salientadas acima ou se o Poder Público tiver assumido o ônus de implementar uma regularização fundiária no local, admitindo com este procedimento a obrigação no caso concreto pelo direito à moradia dos habitantes. (...) A posse, assim como a propriedade, consiste em um bem jurídico merecedor da devida proteção pelo Direito com amparo em preceitos constitucionais e infraconstitucionais relacionados ao direito social à moradia. A segurança da posse é conteúdo essencial ao direito da moradia, razão pela qual a sua perda deve ser devidamente indenizada nos procedimentos de remoção do Município de Belo Horizonte a fim de evitar o empobrecimento daqueles que têm suas moradias demolidas (em virtude das obras implementadas pelo poder público) e a violação do direito 
constitucional da prévia e justa indenização prevista no artigo $182, \S 3^{\circ}$ da CF e do próprio direito à moradia, artigos $6^{\circ}$ e 23 , IX também da Constituição Federal.

Conquistando-se extrajudicialmente a justa indenização dos possuidores a serem removidos evitam-se demandas judiciais, e promove-se, de modo mais eficaz, a regularização fundiária que envolve a população de baixa renda, beneficiando-a, assim como beneficia também o poder público ao facilitar o trâmite e materialização do procedimento de demarcação urbanística e da regularização fundiária a serem promovidos, resguardando ainda o meio ambiente ecologicamente equilibrado.

Seria de se questionar o interesse dos possuidores, que já implementaram os requisitos para a usucapião na modalidade judicial, realizarem a usucapião administrativa inovada pela lei $n .^{0} 11.977$, de 07 de julho de 2009, considerando que, como já dito, esta será a última etapa do longo procedimento administrativo, sendo que o prazo de prescrição aquisitiva somente será contado após o registro da legitimação de posse.

Contudo, acredita-se que a compensação está na demarcação urbanística e no projeto de regularização fundiária que promoverão a inclusão à cidade formal, assegurando-se através do instituto da legitimação de posse, a necessária segurança até a efetiva aquisição do domínio.

\section{Considerações finais}

A falta de planejamento urbano ao longo do século $\mathrm{XX}$, com intensa urbanização aliada a exclusão socioeconômica, refletida também na exclusão espacial nos centros urbanos, levou ao conhecido cenário de assentamos irregulares por população de baixa renda e socialmente vulnerável. Neste contexto, o espaço urbano que restou ao excluído foram as áreas de desinteresse, notadamente econômico, do setor imobiliário, que por vezes coincide com áreas de preservação permanente.

A relação do homem com o meio ambiente sempre foi e sempre será dinâmica. A existência do ser humano implica em interação e, portanto, modificação do meio em que vive. A propriedade urbana cumpre sua função socioambiental 
quando além de atender às exigências fundamentais de ordenação da cidade e assegurar aos cidadãos qualidade de vida, justiça social e desenvolvimento das atividades econômicas, os compatibiliza com o direito ao meio ambiente ecologicamente equilibrado.

A dificuldade da regularização fundiária das ocupações ilegais por população socialmente vulnerável é a sua integração à cidade oficial, garantindo vias de circulação, coleta do lixo e varrição de ruas, iluminação pública, transporte público, aliado a proteção ambiental.

Não se descura da importância das áreas de preservação permanente, mas igualmente não é possível ignorar as longas e consolidadas ocupações existentes em algumas destas áreas no meio urbano. Esse é o desafio de compatibilizar a função socioambiental, equilibrando e respeitando o direito social de moradia e o meio ambiente equilibrado para as presentes e futuras gerações.

O conflito de direitos e interesses é inerente ao procedimento de regularização fundiária, que é um procedimento necessário para corrigir, ou pelo menos mitigar, o passivo da ausência de políticas sociais habitacionais por décadas.

A Defensoria Pública é uma das instituições estatais que visa concretizar os objetivos fundamentais da República Federativa do Brasil, em especial, a construção de uma sociedade livre, justa e solidária, a erradicação da marginalização e redução das desigualdades sociais, e a promoção do bem de todos, sem preconceitos e qualquer forma de discriminação. Nesta senda, é missão constitucional da Defensoria Pública, ao atuar na defesa da regularização fundiária em prol da população socialmente vulnerável, gerar e fomentar o empoderamento popular, através da educação em direitos, da atuação em rede, da promoção de fóruns de debates e audiências públicas, da articulação com os movimentos sociais e populares. O Defensor Público, como agente de transformação social, deve estar próximo de seus assistidos, buscando o conhecimento da real demanda daquela parcela da população, de modo a legitimar a representação institucional desta coletividade.

A regularização fundiária beneficia não somente as comunidades diretamente atingidas, como toda a cidade, uma vez que reflete no território urbano e no planejamento municipal. A regularização formal do parcelamento e a titulação dos REVISTA DO DIREITO UNISC, SANTA CRUZ DO SUL 
moradores, o que se alcança pelas modalidade judiciais de usucapião, sem a devida intervenção urbanística e ambiental implicará na manutenção da precariedade urbana e alijamento deste contingente populacional dos benefícios e serviços públicos da cidade.

Assim, visando concretizar a regularização fundiária, a Defensoria Pública, como instrumento da política urbana de assistência jurídica gratuita para as comunidades e grupos sociais menos favorecidos, deve agir de modo articulado com os movimentos sociais e populares com o fito de potencializar a voz destes, assegurado seus direitos estabelecidos, não só perante o poder judiciário, mas principalmente perante o poder público.

A moradia regular é condição para a realização integral de outros direitos constitucionais, como o trabalho, o lazer, a educação e a saúde, o que implica na materialização da dignidade da pessoa humana, aliada a preservação ambiental para as presentes e futuras gerações.

A mesma Constituição que protege o meio ambiente, protege e ampara o homem, seus direitos fundamentais e sociais, como o de moradia, resguardando de variadas formas a dignidade humana, e ainda garante o desenvolvimento econômico. A redução das desigualdades sociais e regionais constitui objetivo da República Federativa do Brasil. A proteção constitucional do meio ambiente é qualificada pela expressão ecologicamente equilibrado, reconhecendo-o como bem de uso comum do povo e essencial à sadia qualidade de vida. É na compatibilização da proteção ambiental e da dignidade humana que se constrói o dito desenvolvimento sustentável.

\section{REFERÊNCIAS}

ALFONSIN, B. Direito à moradia: instrumentos e experiência de regularização fundiária nas cidades brasileiras. Rio de Janeiro: Observatório de Políticas urbanas, 1997.

ARAUJO, Pedro. "Regularização fundiária urbana em APP: a nova perspectiva trazida pela Lei Federal 11.977/2009". In: Anais do Seminário Nacional sobre Áreas de Preservação Permanente em Meio Urbano. Natal: n.02, 2012. BRASIL. Constituição (1988). Constituição da República Federativa do Brasil. Brasília: Senado Federal, 1988. Disponível em: < $\underline{\text { http://www.senado. }}$ 
gov.br/legislacao/const/con1988/CON1988_06.03.2014/CON1988.shtm> . Acesso em: 06 mar. 2014.

BRASIL. Lei n. 10.257, de 10 de julho de 2001. Regulamenta os arts. 182 e 183 da Constituição Federal, estabelece diretrizes gerais da política urbana e dá outras providências.

Disponível em: $<$ http://www.planalto.gov.br/ccivil_03/leis/leis_2001//10257.htm>. Acesso em 06 mar. 2014.

BRASIL. Lei N.11.977, de 07 de julho de 2009. Dispõe sobre o Programa Minha Casa, Minha Vida - PMCMV e a regularização fundiária de assentamentos localizados em áreas urbanas; altera o Decreto-Lei no 3.365, de 21 de junho de 1941 , as Leis nos 4.380 , de 21 de agosto de 1964, 6.015, de 31 de dezembro de 1973, 8.036, de 11 de maio de 1990, e 10.257, de 10 de julho de 2001, e a Medida Provisória no 2.197-43, de 24 de agosto de 2001; e dá outras providências. Disponível em: <http://www.planalto.gov.br/ccivil_03/_ato20072010/2009/lei//11977.htm > . Acesso em: 06 mar. 2014.

BENJAMIM, Antônio Herman de Vasconcellos. Introdução ao direito ambiental brasileiro. Revista de Direito Ambiental, São Paulo. v.1, p. 14-48. Abr-jun/1999.

CAPPELLETTI, Mauro; GARTH, Bryant. Acesso à justiça. Trad. Ellen Gracie Northfleet. Porto Alegre: Sérgio Antônio Fabris, 2002.

CARVALHO, Leandro Coelho de. As atribuições da Defensoria Pública sob a ótica do acesso à ordem jurídica justa. In: Revista de Processo. São Paulo: v.33, n.156, p.204-224, fev.2008.

COSTA, Beatriz Souza. Meio Ambiente como direito à vida: Brasil, Portugal, Espanha. Belo Horizonte: O Lutador, 2010.

FERNANDES, Edésio. Preservação ambiental ou moradia? Um falso conflito. In: ALFONSIN, Betânia; FERNANDES, Edésio (Org.). Direito Urbanístico: estudos brasileiros e internacionais. Belo Horizonte: Del Rey, p.356-358, 2006.

FIORILLO, Celso Antônio Pacheco. Curso de Direito Ambiental Brasileiro. 14 $4^{\mathrm{a} e d .}$ São Paulo: Saraiva, 2013.

FONSECA, Daniela Rodrigueiro Peres. A dignidade da pessoa humana: razão de existência das tutelas ambientais. Revista do Instituto de Pesquisas e Estudos, Bauru, n. 29, p.287-294, ago./nov. 2000.

GRINOVER, Ada Pelegrini. Parecer,16 de setembro de 2008. Consulente: Associação Nacional de Defensores Públicos - ANADEP, a respeito da arguição de inconstitucionalidade do inciso II do artigo $5^{\circ}$ da Lei da Ação Civil Pública - Lei n. 7.347/85 -, com a redação dada pela Lei n.11.488/2007, em discussão na Ação Direta de Inconstitucionalidade ADIN n. 3943, Relatora Ministra Carmen Lúcia. Disponível em: 
$<$ http://www.anadep.org.br/wtksite/cms/conteudo/4820/Documento10.pdf>. Acesso em 07 mar. 2014.

MACHADO, Paulo Affonso Leme. Direito ambiental brasileiro. 21.ed. rev., atual e ampl. São Paulo: Malheiros, 2013.

MARICATO, Ermínia. Informalidade Urbana no Brasil: a lógica da cidade fraturada. In: Luiz Eduardo Wanderley e Raquel Raichelis (org.). A cidade de São Paulo: relações internacionais e gestão pública. São Paulo: EDUC PUC-SP, 2009, p. 269-292.

MARICATO, Ermínia. Conhecer para resolver a cidade ilegal. In: Leonardo Basci Castriota (org.). Urbanização Brasileira - Redescobertas. Belo Horizonte: Ed. C/Arte, 2003, p. 78-96.

MARQUES, José Roque Nunes. A Constituição Federal e o meio ambiente. Cidadania e Justiça, Rio de Janeiro, v. 4, n. 9, p.26-31, 2000.

MOREIRA, J. C. Tutela jurisdicional dos interesses coletivos ou difusos. Temas de Direito Processual, Terceira Série, 1984.

NEPOMUCENO, Cleide Aparecida. Os movimentos populares e a defensoria pública na construção de um diálogo democrático. In ROCHA, Amélia [et al.] (Org.). Defensoria Pública, Assessoria Jurídica Popular e Movimentos Sociais e Populares: novos caminhos traçados na concretização do direito de acesso à justiça. Fortaleza: Dedo de Moças Editora e Comunicação Ltda, p.153-168, 2013.

PONTES, Daniele Regina; FARIA, José Ricardo Vargas de. Regularização fundiária: análises. In: Planeta Amazônia: Revista Internacional de Direito Ambiental e Políticas Públicas. Macapá, n. 2, p. 189-202, 2010.

SARLET, Ingo Wolfgang; FENSTERSEIFER, Tiago. Breves considerações sobre os deveres de proteção do Estado e a garantia da proibição de retrocesso em matéria ambiental. Revista de Direito Ambiental, São Paulo, v. 15, n. 58, p.41-85, abr./jun. 2010.

SILVA, José Carlos Alves da. Favelas e Meio Ambiente Urbano. DALLARI, Adilson Abreu; SARNO, Daniela Campos Libório Di (Org.). Direito Urbanístico e Ambiental, Belo Horizonte, p.223-244, 2011. 